03;04

\title{
Влияние объемного заряда на перенос заряженных частиц, генерируемых при электрораспылении в скрещенных газодинамическом и электрическом полях
}

\author{
(C) И.А. Громов, Н.С. Самсонова, Н.Р. Галль
}

Физико-технический институт им. А.Ф. Иоффе РАН, Санкт-Петербург, Россия

E-mail: gromov-24-2@yandex.ru

Поступило в Редакцию 31 июля 2018г.

В окончательной редакции 22 ноября 2018г.

Принято к публикации 22 ноября 2018 г.

Исследован транспорт заряженных частиц, образующихся при электрораспылении, в продольном газодинамическом поле в модельной системе, состоящей из двух соосно расположенных электродов и коллектора-сетки. Проведены компьютерные симуляции процесса в пренебрежении ролью объемного заряда. Сравнение полученных результатов показывает, что именно объемный заряд является ключевым фактором, определяющим транспорт заряженных частиц: без него эффективность переноса достигает 80-100\%. В эксперименте же эта величина радикально зависит от величины объемного заряда и составляет 70-80\% при минимально доступных его величинах, снижаясь до 20-30\% с увеличением тока электрораспыления.

DOI: 10.21883/PJTF.2019.04.47333.17482

В настоящее время электрораспыление широко применяется в науке и технике: от масс-спектрометрии биополимеров (ESI MS) до получения изображения в струйных принтерах. В масс-спектрометрии электрораспыление обычно реализуется в потоке спутного газа, движущемся параллельно оси распыления [1], что позволяет увеличивать его стабильность. В последние годы электрораспыление в потоке газа применяется для решения ряда близких задач, например для десорбции заряженных частиц с поверхности твердого образца $[1,2]$ и проведения химических реакций „вне колбы“, непосредственно в образующихся каплях $[3,4]$. Физика процесса электрораспыления широко изучалась в течение длительного времени [5,6], однако авторы работ были сосредоточены, как правило, на процессах, протекающих на кончике конуса Тейлора, где происходит эмиссия заряженных капель. При этом в значительной мере игнорировалась роль объемного заряда, возникающего между распылительным капилляром и противоэлектродом, который в случае, например, коронного разряда играет определяющую роль. Как показано в [7], эта величина является причиной осцилляций распыления и сложным самосогласованным образом зависит от токов, напряжений и расстояния между электродами. Добавление в систему газовых потоков резко усложняет картину, и адекватной теории, описывающей протекающие процессы, до сих пор нет. Целью настоящей является оценка влияния объемного заряда на транспорт заряженных частиц, образующихся при электрораспылении, в потоке спутного газа, что позволит расширить представления о движении заряженных частиц в газодинамическом и электрическом полях.

Исследования проведены на экспериментальном стенде, позволяющем получить электрораспыление жидкости и коронный разряд при атмосферном давлении в продольном потоке спутного газа (рис. 1). Заряженные частицы 7 генерируются на торце распылительного капилляра 3 с внутренним диаметром $0.35 \mathrm{~mm}$, закрепленного соосно с противоэлектродом 9 в форме кольца с внутренним диаметром $12 \mathrm{~mm}$ так, что его выходной срез располагается в плоскости данного электрода. В качестве коллектора установлена металлическая сетка в форме полусферы 8 . Коллектор закреплен так, что его положение относительно торца капилляра 3 изменяется в диапазоне расстояний $R=4-40 \mathrm{~mm}$. Электрический ток на коллектор 8 и противоэлектрод 9 измерялся с помощью цифровых приборов 10 с входным сопротивлением $1 \mathrm{M} \Omega$.

Поток газа направлен вдоль распылительного капилляра так, как показано на рис. 1, со скоростью около $8 \mathrm{~m} / \mathrm{s}$, рассчитанной как отношение потока газа компрессора к площади поперечного сечения отверстия противоэлектрода. Электрораспыление проходило со скоростью подачи жидкости $3 \mu \mathrm{l} / \mathrm{min}$, устанавливаемой с помощью шприцевого насоса 2. В качестве распыляемой жидкости использовался раствор $\mathrm{CsCl}$ с концентрацией $10^{-3} \mathrm{M}$ в водно-этанольном растворителе в соотношении 8:2. Коронный разряд формировался при тех же условиях, но без подачи жидкости. Значения используемых напряжений находятся в интервале от 2.1 до $4 \mathrm{kV}$.

$\mathrm{B}$ экспериментах измерялись зависимость электрического тока от напряжения электрораспыления жидкости (или коронного разряда) и распределение тока между коллектором и противоэлектродом. Во всех случаях при отсутствии потока воздуха весь ток как для электрораспыления, так и для коронного разряда приходит только на противоэлектрод.

Компьютерные симуляции движения ионов проводились в программе Ахim-2010, а расчет распределения потенциалов - в программе Simion-8. Расчеты выпол- 


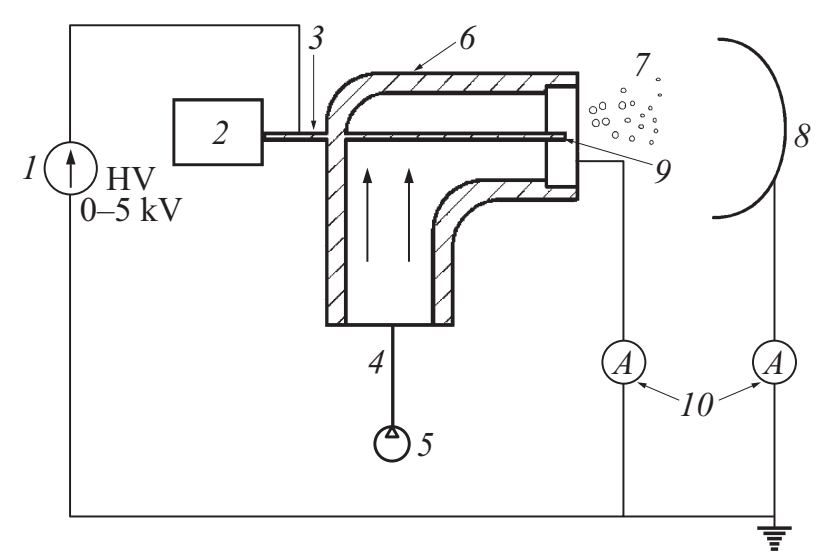

Рис. 1. Схема экспериментальной установки. 1 - источник высоковольтного напряжения; 2 - электрошприцевой насос; 3 - электрораспылительный капилляр/капилляр коронного разряда; 4 -- соединительный патрубок для подвода газа; 5 компрессор для подачи спутного газа; 6 - полипропиленовая труба (стрелками показано направление движения потока воздуха); 7 - область заряженных капель и ионов; 8 коллектор полусферический, выполненный из металлической сетки; 9 - металлический противоэлектрод; 10 - цифровые устройства измерения электрического тока на коллектор и противоэлектрод.

нены в приближении Лапласа; использовалась модель, соответствующая экспериментальной установке. Поток воздуха принимался однородным и незатухающим. Для симуляций использовались ионы с массовым числом $133 \mathrm{Da}$ и подвижностью $2.5 \cdot 10^{-4} \mathrm{~m}^{2} /(\mathrm{V} \cdot \mathrm{s})$ [8]. Результаты расчета показаны на рис. 2 (кривые 1,2), поперечный разброс составляет $\pm 1 \mathrm{~mm}$ от оси коаксиальной системы. Доля тока рассчитана как отношение числа долетевших до коллектора заряженных частиц к их общему количеству.

На рис. 2 (кривые 3-6) представлены экспериментальные зависимости отношения тока на коллекторе $I_{c}$ к общему току $I_{t o t}$ от напряжения, прикладываемого к распылительному капилляру, в режиме электрораспыления жидкости. Данные получены при постоянном расстоянии между противоэлектродом и коллектором. Видно, что при увеличении расстояния до коллектора на него приходится все меньшая доля общего тока, причем с ростом общего тока электрораспыления, т. е. с увеличением напряжения распыления, доля тока, приходящегося на коллектор, также снижается.

Качественно такое же соотношение токов заряженных частиц справедливо и для режима коронного разряда. На рис. 3 представлены результаты измерений для $R=4$ (a) и $20 \mathrm{~mm}(b)$. Видно, что при $R=4 \mathrm{~mm}$ доля тока на коллектор одинакова как для электрораспыления жидкости, так и для ионизации в коронном разряде, а в случае увеличения расстояния $(R=20 \mathrm{~mm})$ заряженные частицы, полученные при электрораспылении, переносятся более эффективно, чем при коронном разряде. Отметим, что при одинаковом общем токе $I_{t o t}$ коронный разряд загорается при напряжении, равном $3.4 \mathrm{kV}$, а электрораспыление начинается при $2.1 \mathrm{kV}$.

Таким образом, экспериментально показано, что независимо от метода получения заряженных частиц как для ионной составляющей, так и для смеси заряженных капель и ионов доля тока, уносимого газом и достигающего коллектора $I_{c}$, не превышает 90\% и сильно зависит от величины общего тока $I_{t o t}$. Однако расчеты показывают (кривые 1 и 2 на рис. 2), что в приближении Лапласа доля тока для ионов с подвижностью $2.5 \cdot 10^{-4} \mathrm{~m}^{2} /(\mathrm{V} \cdot \mathrm{s})$ в несколько раз больше, чем в эксперименте.

Причина указанного расхождения между расчетом и экспериментом кроется в учете объемного заряда. Скорость заряженных частиц определяется скоростью дрейфа в поле, зависящей от подвижности частицы, и скоростью газа, переносящего эти частицы. Сама же величина поля определяется поданными на электроды потенциалами и объемным зарядом, образуемым всеми заряженными частицами.

Расчет поля, создаваемого внешними потенциалами в данной геометрии, показывает, что оно в основном направлено от распылительного капилляра к противоэлектроду, т.е. поперек направления переноса заряженных частиц к коллектору. У этого поля имеется лишь незначительная „продольная“ составляющая, расположенная на некотором удалении от оси движения. Наоборот, газовый поток направлен к коллектору. При диаметре выходного патрубка $12 \mathrm{~mm}$ на расстояниях порядка 5-40 mm его скорость можно считать постоянной: она упадет не более чем на $30-40 \%$ на максимальных удалениях, используемых в эксперименте [9]. Что касается поля объемного заряда, то оно направлено так, что препятствует движению частиц к коллектору и приводит

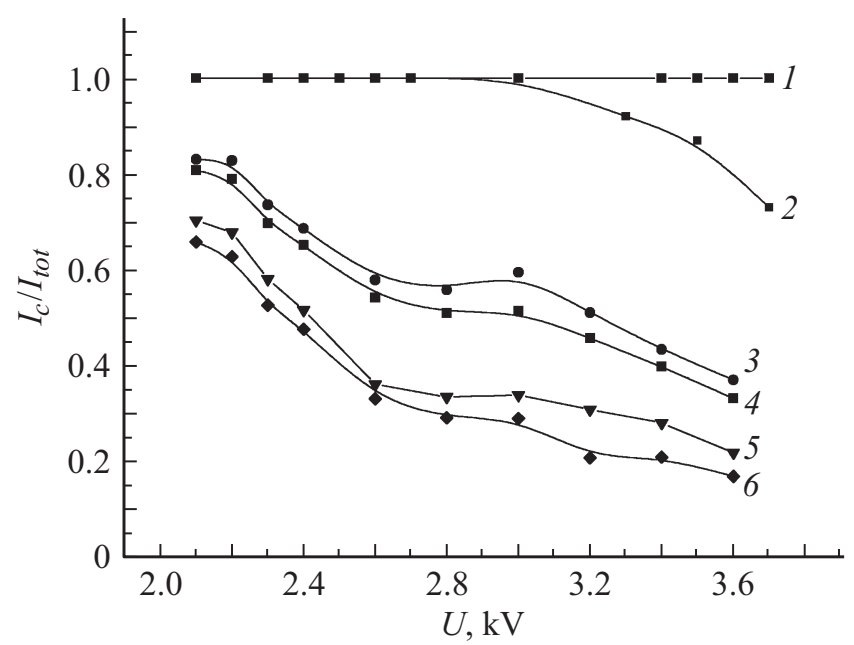

Рис. 2. Зависимость доли тока на коллектор от напряжения на распылительном капилляре в коаксиальной системе при наличии потока воздуха. 1, 2 - кривые, полученные из теоретических симуляций, 3-6- экспериментальные кривые, полученные при электрораспылении. Кривые соответствуют расстояниям между противоэлектродом и коллектором, равным $4(1,3), 28(2,6), 8(4)$ и $20 \mathrm{~mm}(5)$. 

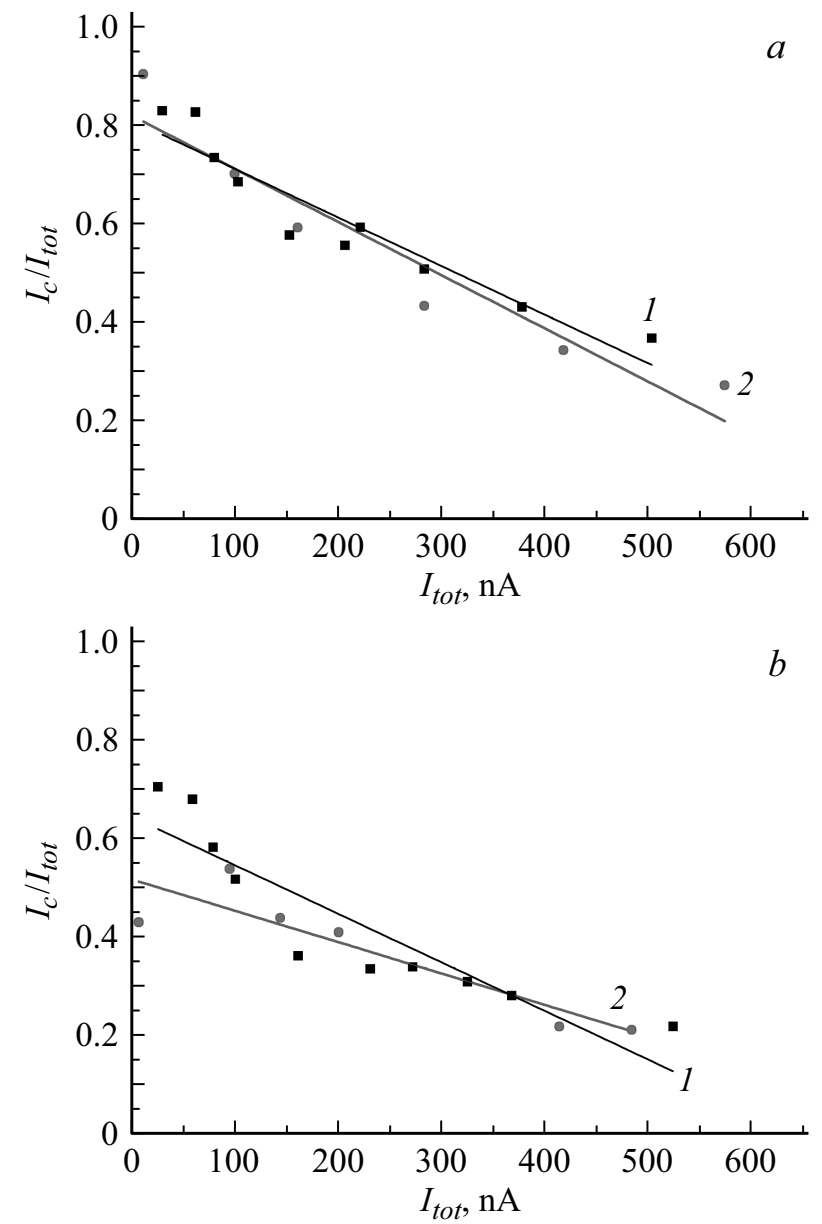

Рис. 3. Сравнительные зависимости доли тока на коллектор от общего тока для электрораспыления (1) и коронного разряда (2) при расстоянии между кольцевым электродом и коллектором $R$, равном $4(a)$ и $20 \mathrm{~mm}(b)$.

к их возвращению на противоэлектрод; это является единственным фактором, способным обеспечить такое возвратное движение.

Из сравнения расчетных данных, в которых влияние объемного заряда не учитывается, и экспериментальных результатов видно, что в симуляции до коллектора долетает от 80 до $100 \%$, а в эксперименте тот же параметр значительно падает с ростом полного тока распыления, так как поле объемного заряда усиливается с ростом общего тока. Влияние объемного заряда приводит к тому, что доли тока, переносимые на коллектор при электрораспылении и коронном разряде, сопоставимы (рис. 3,a). Казалось бы, из-за разницы в подвижностях заряженных капель, генерируемых в электрораспылении, и ионов, генерируемых в коронном разряде [10], ионы должны более эффективно притягиваться к противоэлектроду электрическим полем, тогда как капли должны более эффективно переноситься газом на коллектор, но этого не происходит. Однако при предельно малом общем токе $I_{t o t}$ (менее $380 \mathrm{nA}$, что соответствует границе стабильности коронного разряда) эффективность переноса капель на коллектор выше, чем для ионов, что особенно заметно при увеличении расстояния до коллектора (рис. $3, b$ ).

Таким образом, объемный заряд служит одним из ключевых факторов, определяющих транспорт заряженных частиц, которые образуются при электрораспылении, в том числе и при использовании газовых потоков. Величина объемного заряда является сложной самосогласованной функцией состава факела заряженных частиц, величин токов, напряжений и скоростей газовых потоков. Наибольшее значение объемный заряд имеет при значительных межэлектродных расстояниях.

\section{Список литературы}

[1] Gross J.H. Mass spectrometry. 3rd ed. Cham, Switzerland: Springer International Publ., 2017. 968 p.

[2] Dong Y., Guella G., Mattivi F., Franceschi P. // J. Am. Soc. Mass Spectrometry. 2015. V. 26. N 3. P. 386-389.

[3] Лебедев А.Т. // Успехи химии. 2015. Т. 84. № 7. С. 665-692.

[4] Badu-Tawiah A.K., Campbell D.I., Cooks R.G. // J. Am. Soc. Mass Spectrom. 2012. V. 23. N 6. P. 1077-1084.

[5] Electrospray and MALDI mass spectrometry: fundamentals, instrumentation, practicalities, and biological applications / Ed. R.B. Cole. 2nd ed. Hoboken: Wiley, 2010. 847 p.

[6] Григорьев А.И., Ширяева С.О. // ЖТФ. 2012. Т. 82. В. 10. C. 7-17.

[7] Фомина Н.С., Масюкевич С.В., Галль Л.Н., Галль Н.Р. // Масс-спектрометрия. 2015. Т. 12. № 4. С. 222-228.

[8] Таблицы физических величин: справочник / Под ред. И.К. Кикоина. М.: Атомиздат, 1976. 1008 с.

[9] Теория турбулентных струй / Под ред. Г.Н. Абрамовича. 2-е изд., перераб. и доп. М.: Наука, 1984. 716 с.

[10] Фомина Н.С., Масюкевич С.В., Свиридович Е.Н., Галль Н.Р. // Приборы и техника эксперимента. 2014. № 2. C. 139-144. 